\title{
CRISE DO CAPITALISMO AGRÁRIO E SOLUÇÃO CATÓLICA, NO PARANÁ
}

Peri Mesquida e Altair Anacleto Lorenzetti *

\section{Intıo d u çã o}

De acordo com Antonio GRAMSCI(1975,p.1134-5), duas organizações desempenham na sociedade a função de organização cultural: a escola e a igreja. Elas têm grande importância, pois abrangem totalmente o domínio da ideologia, influindo diretamente sobre a formação da opinião pública e para 0 estabelecimento do consenso através do senso comum. A Igreja luta para que não haja uma ruptura entre as classes superiores e as inferiores(1975, p. 978), mantendo a unidade ideológica através da política e da evolução ideológica progressiva, conservando uma certa homogeneidade no seu bloco ideológico(1975, p. 979), em especial através da organização escolar, quando esta se encontra sob o seu domínio. Isso significa que a Igreja ao mesmo tempo em que atua através da "filosofia" junto à elite, transforma esta em senso comum para as camadas inferiores da sociedade. Dessa maneira, a Igreja auxilia a sociedade política, cujo aparelho de Estado está nas mãos da elite, a exercer a hegemonia política sobre a sociedade civil, sem que seja necessário o uso ostensivo da coerção. Assim, se estabelece o consenso em torno dos atos originados do aparelho de Estado.

No Brasil, segundo OLIVEIRA(1985, pgs. 205-230), os proprietários do capital agrário são a classe dominante nas formações social de capitalismo agrário. Mas, para que uma classe social possa exercer sua dominação de modo durável, não basta que ela detenha os principais meios de produção; é preciso também que ela exerça o poder de Estado, que assegura pelos meios

* Professores do Curso de Mestrado em Educação, PUCPR. 
legais a ordem estabelecida conforme a orientação imprimida pela classe dominante, e que ela ganhe o consentimento das classes dominadas e subalternas à sua dominação. Não basta que ela seja dominante, precisa, também, ser dirigente, isto é, deve exercer a hegemonia política e social para que sua dominação seja durável. É o exercício da hegemonia social que a torna classe hegemônica.

Nossa pesquisa procurará inicialmente, descortinar os instrumentos que os agropecuaristas, em especial do Paraná, utilizaram para assegurar sua hegemonia.

\section{I - Hegemonia política gamiza ção do Esta dep urblica - n o}

Partimos do pressuposto de que o capitalismo agrário instaura-se ao mesmo tempo em que nasce uma nova classe agrária: a dos fazendeiros que atuam com relações capitalistas de trabalho, e lutam desde o início pela hegemonia política e social, gerando uma crise de hegemonia que afeta diretamente a função social da religião.

Nossa análise adota como princípio que as transformações porque passa o catolicismo, as quais aqui denominamos simplesmente de "romanização", não são simples efeito das transformações econômicas, sociais e políticas, mas guardam uma interdependência, já que as funções sociais da religião só podem ser desvendadas dentro do quadro global da estrutura e do funcionamento do todo social.

Defendemos a tese, seguindo OLIVEIRA (1985), de que a abolição da escravatura não foi o fator principal da queda do império; o que estava em jogo na proclamação da República era a descentralização do Estado. Os grandes proprietários rurais queriam o federalismo onde cada Estado tivesse autonomia. A federação republicana viria atender a esse interesse, levando à concentração de riqueza nos Estados mais prósperos e fortes(São Paulo, Minas Gerais e, posteriormente, Rio Grande do Sul), enquanto os outros estados ficavam entregues à própria sorte. Entretanto, era preciso não enfraquecer muito a União, pois ela era importante não só para manter a unidade nacional como também para regular o comércio exterior. Assim, desse jogo de forças entre um federalismo extremado (e interesseiro) e um Estado de poder centralizado nasce a I República. Formalmente democrática, ela será controlada na prática pela composição das oligarquias estaduais (CARONE,251-320).

A federação republicana corresponde aos interesses do setor agroexportador: o imposto sobre as exportações favorece os Estados ricos, enquanto o imposto sobre as importações, que afeta o custo de vida do conjunto da sociedade, vai para a União; as terras públicas ficam com os Estados, facilitando às oligarquias locais o controle sobre sua distribuição; fica aberta a 
possibilidade de intervenção federal nos Estados que não se alinham à política do governo federal, controlado pelas oligarquias dos Estados mais fortes.

A organização política da classe dominante não passa pelos partidos, simples máquinas eleitorais, mas pelo sistema do coronelismo(complexo sistema de hierarquias e lealdades, herdado do Império). O coronel é o chefe político local, sendo normalmente um grande proprietário de terras e, em alguns casos, comerciante, advogado ou médico. Ele é o cume do poder local, desempenhando o papel de conceder terras a seus protegidos, prender e absolver, dar empregos públicos, fazer a mediação entre o poder local e 0 estadual, enfim, pelo coronel passa toda decisão que afeta a vida local. $\mathrm{Na}$ realidade, as autoridades públicas não fazem mais do que ratificar e executar as decisões por ele tomadas, sem que fique demarcada a linha que separa 0 interesse público do interesse privado..

O poder federal não é mais do que a expressão das decisões tomadas pelas oligarquias estaduais. O candidato do governo a presidente da República tem sempre o apoio das oligarquias que o elegeram e a elas presta serviço. Assim, o presidente da República tem sempre o apoio das oligarquias dos estados mais poderosos(São Paulo e Minas Gerais), do qual dependia, fundamentalmente, o equilíbrio do sistema. Em 1930, o Rio Grande do Sul, que havia desenvolvido uma significativa economia interna, contesta a aliança São Paulo - Minas Gerais, e contando com apoio do Exército, enfraquece substancialmente o sistema coronelístico-oligárquico da I República. Ocorre a ascensão das classes médias urbanas, já que o modo de produção capitalista começa a assumir uma nova forma.

\section{II - Crise de hegemonia social}

A instalação do capitalismo agrário não apenas altera as relações de produção (abolição da escravatura e instalação do trabalho assalariado) e 0 sistema político, com a formação de uma nova classe politicamente hegemônica, mas provoca uma crise de hegemonia social. Salvo as Câmaras Municipais, todas as instituições sociais se desestruturam com a proclamação da república (Carone, 1978, pgs. 147-250).

Esta crise tem uma dupla dimensão: por um lado, desmoronam as instituições estabelecidas pela formação social senhorial, com a função de promover a hegemonia social ( destaque para a Igreja Católica); por outro lado, a nova classe dominante não conta com formas ideológicas e aparelhos de hegemonia capazes de ganhar o consentimento das classes subalternas à sua dominação.

A classe dominante irá tentar organizar a vida coletiva conforme sua orientação fundamental por meio dos "bacharéis" (seus intelectuais orgâni- 
cos). No sentido estrito, bacharel é a pessoa formada em Direito, Filosofia ou Letras; porém no uso corrente do início do século, usa-se a palavra "bacharel" para designar quem tenha curso universitário marcado por uma formação com verniz humanista, ainda que seja médico ou engenheiro. Os bacharéis constituem desde o final do império, uma camada de intelectuais cuja formação jurídica e humanista os predispõe para o exercício de atividades políticas. Eles são o complemento indispensável do coronelismo.

Para que o coronel possa exercer seu papel de mediador entre os poderes públicos e os grupos situados em sua área de influência, precisa ter relações com os bacharéis que ocupam os postos de governo. É justamente devido à influência política do coronel ao qual está ligado o bacharel que este obtém sua nomeação para os cargos públicos ou garante sua eleição. As carreiras política, administrativa e judiciária dependem, antes de tudo, do coronel que faz valer sua influência para obter nomeações e para garantir a eleição de seus candidatos. Por isso, o fato de o bachareal ser ou não proprietário de terra é de menor importância, posto que sua carreira depende do coronel ao qual está ligado. Assim, ele não pode deixar de lhe ser leal nem contrariar seus interesses. Em suma, o bacharel é aquele que exprime, no campo político e cultural, os interesses do coronel poderoso, mas rude (CARONE, id.).

Esse laço orgânico entre o bacharel e o coronel é a chave para a explicação da produção cultural e ideológica dos bacharéis. Apesar de viverem nas cidades, os bacharéis exprimem uma ideologia agrária, ao dizer que a vocação do Brasil é agrícola, por exemplo; necessidade de proteger o setor agroexportador; o campo é um espaço romântico e sem conflitos, que faz do Brasil um país rico, belo, pacífico e de futuro promissor. Para o bacharel, sua produção ideológica não é uma exaltação do passado, mas uma ideologia do progresso. A importação de instituições da Europa e dos Estados Unidos é vista como a forma de introdução no Brasil do progresso (Teatros Municipais, Biblioteca Nacional, Escolas de Belas Artes; Colégios protestantes, católicos, etc.).

O bacharel é o intelectual orgânico da classe dominante agrária. Ele difunde no campo político, administrativo, judiciário, cultural, artístico, bem como nas escolas e na imprensa, a idéia de que o progresso do Brasil será assegurado na medida em que as liberdades individuais forem respeitadas, em que o povo receber educação adequada, em que o Estado apoiar a grande lavoura e fizer respeitar a ordem estabelecida. É devido a esse trabalho intelectual que os bacharéis ocupam posição de tanta importância na I República, sustentando ideologicamente as oligarquias agrárias, cujo substrato ideológico é essencialmente positivista.

Se os bacharéis detêm o quase - monopólio da produção cultural erudita e ocupam os melhores postos na política, na administração e no judiciário, sendo contestados somente pela jovem oficialidade militar, o clero ca- 
tólico e alguns intelectuais rebeledes (Euclides da Cunha e Lima Barreto, por exemplo) (OLIVEIRA, 1985, pgs. 223 - 237 ), não significa que seu raio de influência seja grande sobre o conjunto da população. A influência dos bacharéis é grande no mundo político, administrativo, judiciário e cultural, mas esses mundos são pequenos. Limitam-se às grandes cidades, ficando alheios ao mundo rural onde vivem milhões de brasileiros (FAORO, Vl. 2, 1995, pg. $621)$.

Segundo CARONE(op.cit, pg. 223-237), diante de tal quadro, a incorporação da massa da população ao modo de produção capitalista era um problema, uma vez que para o funcionamento do capitalismo é necessário que haja indivíduos dispostos a vender sua força de trabalho. Para que haja indivíduos dispostos a vender sua força de trabalho é necessário que estejam destituídos da propriedade dos meios de produção e sem laços de dependência pessoal. A realidade rural brasileira era bem outra. Os laços de dependência pessoal estabelecidos pela formação social senhorial estavam arraigados no inconsciente da massa camponesa, e se não tinham a propriedade da terra, tinham a posse da terra de maneira estável. Por essa razão é que o capitalismo agrário brasileiro se inicia com os imigrantes europeus ( CARONE, op.cit., Vl. I, pgs. 11-14). A grilagem e a restrição da concessão de terras a quem não as possa comprar são o instrumento de coerção das oligarquias rurais para introduzir a massa camponesa no capitalismo agrário. Porém, a coerção é insuficiente para esse processo. Não basta destituir o camponês de seus meios de produção, para que ele se transforme em vendedor da força de trabalho. É preciso também ganhar o seu consentimento, fazendo-o ver a vantagem em transformar-se em trabalhador assalariado. Porém, esse trabalho ideológico, indispensável ao funcionamento ao modo de produção capitalista , estava fora do alcance dos bacharéis, uma vez que sua produção ideológica é destinada ao mundo urbano. Por sua parte, o camponês, coagido, reagia intensificando sua produção religiosa na qual encontra um modelo de ordem social fundado na aliança entre poderosos e fracos e não nas frias relações sociais reguladas pelo mercado. Tal produção religiosa ganha forma de protesto social, que na realidade é a caracteństica dos conflitos sociais da I República ( OLIVEIRA, op.cit., 1985, pg. 222-240).

\section{III - A Iqjja Católica no Brasil no século XIX: crise d catolicismo clerical}

O catolicismo é a única religião oficialmente admitida no Brasil até a proclamação da república. Embora a legislação do império tenha introduzido alguma tolerância religiosa, o catolicismo permaneceu como religião oficial do Estado até 1890, quando se dá a separação entre Igreja e Estado. Ser cristão 
católico era condição indispensável para o direito de cidadania e até para poder receber sesmaria. O catolicismo implantou-se pois no Brasil como religião do Estado, sendo um dos elementos essenciais da empresa colonial portuguesa. As relações entre Estado e Igreja católica desempenhavam um papel fundamental no século XIX, principalmente num país como o Brasil, que ainda mantinha a mesma relação com o catolicismo sob o qual nascera no século XVI, pelo fato de ser colônia portuguesa. Sérgio Buarque de Holanda esclarece que "em consequência do grão-mestrado da Ordem de Cristo, sobretudo depois de confirmada em 1551 por Sua Santidade o Papa Júlio III, na bula Praeclara carissima" (HOLANDA, 1968, pg. 84), a Igreja Católica estava subordinada aos mandatários do poder civil nas terras descobertas. Estes, "propunham candidatos ao bispado e nomeavam-nos com cláusula de ratificação pontifícia, cobravam dízimos para dotação do culto e estabeleciam toda sorte de fundações religiosas, por conta própria e segundo suas conveniências. A Igreja transformara-se, por esse modo, em simples braço do poder secular, em um departamento da administração leiga" (HOLANDA, op.cit. p. 84).

O regime do padroado fazia dos bispos funcionários públicos encarregados do culto religioso, dependentes do Governo Imperial de direito e de fato ( pois dele dependiam para seu sustento e para a manutenção das atividades eclesiásticas). Dispensavam até mesmo o apoio da Santa Sé, posto que as bulas papais dependiam do "placet" imperial para ter valor legal, e nem sempre este era concedido ou só o era em parte. Sua função, exercida através dos ritos religiosos, era manter o sistema.

O direito ao governo eclesiástico era exercido por meio do aparelho burocrático do Estado: a Mesa de Consciência e Ordens, durante o período colonial, e o Ministério da Justiça, durante o período imperial. Era o rei, e depois o imperador, quem decidia sobre a criação de dioceses e paróquias, a instalação de ordens religiosas e fundação de conventos, a nomeação para os postos eclesiásticos, e, até mesmo, a aprovação de documentos eclesiásticos.

As ordens religiosas dos jesuítas, franciscanos, beneditinos e carmelitas, que constituíam a espinha dorsal da Igreja Católica durante o período colonial, estavam em franca decadência no século XIX. Os jesuítas expulsos em 1759, os franciscanos, beneditinos e carmelitas, minados por interferências externas de leigos e lutas internas, estavam às portas da extinção e os bispos não podiam mais contar com elas para a atividade pastoral e direção de escolas, ao contrário, a preocupação era reformá-las (AZZI 1974,pg646-647).Sobrava o que se convencionou chamar de "clero secular". A disciplina do clero regular, a auto-suficiência financeira e uma coordenação central faziam dele um elemento pouco manipulável. Para a empresa colonial portuguesa, um aparelho eclesiástico bem estruturado só foi interessante na fase de conquista do território. Assim, o aparelho religioso católico tem uma sólida organização apenas no momento da conquista colonial, quando as ordens religiosas se 
dedicam ao trabalho de integração dos índios na formação social senhorial. Como esse período se prolonga por dois séculos, à medida que os portugueses avançavam sobre os territórios indígenas, durante todo esse tempo as ordens religiosas contam com o esteio do Estado. Uma vez consolidada a conquista colonial, e estruturada a dominação senhorial, o aparelho eclesiástico perde sua função de agente de conquista dos índios. A partir de então, o aparelho eclesiástico assume a função social de manutenção da unidade religiosa e moral do todo social e a função de organização da vida coletiva; mas para exercê-las, basta-lhe uma organização interna pouco organizada e pouco desenvolvida. Desde que haja um mínimo de articulação entre os agentes religiosos do catolicismo popular e os agentes do catolicismo oficial ( por meio das visitas de desobriga, das missões populares, da presença dos padres nos santuários esporadicamente, pelas capelanias, etc.), a unidade religiosa e moral estava assegurada. Para esta função bastava o clero secular, que na prática é a maioria do corpo eclesiástico durante o século XIX. Uma articulação estrita das massas populares com o aparelho eclesiástico não era desejada pelo Estado ( Tal fato explica porque as disposições do Concílio de Trento quanto à reformulação do aparelho eclesiástico não tenham sido implantadas no Brasil até 1890).

Sobre o clero secular a autoridade dos bispos era fraca. Dispersos pelas paróquias e capelas do interior, ou mais freqüentemente, ganhando a vida como capelães de fazendas ou confrarias, os padres seculares ficavam praticamente fora do alcance da autoridade episcopal. Precariamente formados, sobretudo depois da expulsão dos jesuítas e o conseqüente fechamento de seus seminários, os padres seculares só constituíam a elite letrada do país porque o restante da população era quase toda analfabeta (Macedo Costa, carta, 2/6/1877 - 1982, p. 31-69).

A inoperância do aparelho eclesiástico clerical não significava que as atividades religiosas no século XIX deixassem de ser intensas. Pelo contrário, o catolicismo leigo é a marca religiosa do século XIX, no Brasil. Porém, a religiosidade católica "popular" era um empecilho não apenas para a instauração do capitalismo agrário, mas para o próprio projeto de romanização.

A característica do catolicismo brasileiro durante o século XIX é a de ser um catolicismo dirigido por leigos, cujo núcleo de religiosidade está no culto dos santos. Tal forma de experiência religiosa recebeu o nome de catolicismo luso-brasileiro ou popular, isto é, "o conjunto de representações e práticas religiosas desenvolvidas pelo imaginário popular a partir dos símbolos introduzidos no Brasil pelos missionários e colonos portugueses, e aos quais se juntaram alguns símbolos indígenas e africanos"( OLIVEIRA, 1977).

Os "eremitões" e "beatos" constituíam as lideranças leigas, porém não tinham ligações com as confrarias e irmandades. As lideranças leigas eram homens que se dedicavam à vida ascética, viviam de esmolas, faziam penitên- 
cias e rezavam pelos próprios pecados e pelos pecados alheios. Perambulavam pelo interior, rezavam, benziam, batizavam, casavam e curavam, sendo tidos como homens santos pelo povo, para quem sua reza equivalia a uma missa. Daí a definição do catolicismo brasileiro do século XIX ser a de: "muita reza e pouco missa, muito santo e pouco padre".

Para a classe dominante tal forma de religiosidade era necessária, desde que ela pudesse manter o controle sobre as ações dos beatos e eremitões. Além de precisar manter um aparato eclesiástico desenvolvido, continuamente gerando crises pela resistência que poderia opor, pela defesa da ortodoxia católica, tal forma de religiosidade permitia que em torno de um único código religioso, por sinal maleável, se agregassem variadas expressões de religiosidade, conforme as classes sociais, contribuindo assim para a unidade social e moral.

Além disso, o catolicismo popular não contestava a dominação social vigente, antes a reforçava, na medida em que suas representações religiosas fortaleciam as relações de dominação pessoal existentes. É nesse sentido que o catolicismo desempenha a função social de direção moral e intelectual das massas.

Detentoras do poder econômico e político, as oligarquias rurais capitalistas têm dificuldade de obter a adesão das vontades e a cooperação das classes dominadas, por carecerem de instrumentos de exercício de hegemonia. $\mathrm{O}$ que falta às oligarquias é que os dominados percebam como sendo de seu interesse e dever entrar nas relações capitalistas. Tal crise de hegemonia explica os movimentos religiosos de protesto social durante a primeira república (Contestado, em Santa Catarina; Canudos, e Juazeiro, no Nordeste). Esses movimentos mostram como a produção religiosa camponesa reage à nova ordem social em vigor. Esta oposição radical entre a ordem social vigente e a ordem social "desejada por Deus", é um fato novo na produção religiosa popular. Em suma, com a quebra da dominação pessoal e o fim da ordem social senhorial, é a própria ordem religiosa e moral que fica abalada. Os movimentos religiosos de protesto camponês inscrevem-se, portanto, no processo de dissolução da ordem social senhorial e a instalação do capitalismo agrário, no vácuo deixado pela ausência de uma direção intelectual e moral. Não é pela prática do catolicismo popular que os camponeses lutam, mas pela continuação da ordem social que estava sendo destruída, na qual seu universo mental está estruturado.

Contudo, se o catolicismo no Brasil não submerge diante das teses liberais e do avanço do modo de produção capitalista, mas encontra nele novo lugar e novas funções sociais, ou seja, novas formar de exercício da função social de hegemonia, é porque conseguiu transformar-se internamente para auxiliar no próprio processo de instauração do capitalismo agrário. Tal processo de transformação interna do catolicismo no Brasil não é um proces- 
so endógeno, mas, sim, exógeno. Tal transformação se insere num processo mais amplo de transformações do aparelho religioso católico em escala mundial, processo iniciado após a Revolução Francesa, porém ganhando forma definida com o Papa Pio IX(1846-1878) e levado a cabo com os papas Leão XIII(1878-1903) e Pio X(1903-1914). As características principais da restauração católica são: rejeição da modernidade; centralização do governo da Igreja católica pela Santa Sé; expansão centralizadora das ordens e congregações religiosas; desenvolvimento de novas devoções religiosas; desenvolvimento de um ensino católico paralelo ao oficial, como parte do projeto pastoral.

No processo de transformação do catolicismo brasileiro, o papel da Santa Sé - Papa e a Cúria Romana - é importantíssimo; no fundo, os bispos não fazem mais do que incorporar ao catolicismo brasileiro os modelos de organização eclesiástica, de crenças e de práticas pastorais que a Santa Sé lhes fornece. Mas, o papel da Santa Sé é mais do que o de simples incentivadora da restruturação católica; ao mesmo tempo em que fornece os modelos a serem seguidos estritamente pelos bispos brasileiros, a Santa Sé lhes dá também os meios para torná-los efetivos, isto é, os agentes religiosos. São eles, principalmente as congregações religiosas, masculinas e femininas, de direito pontifício. No fundo, a Santa Sé transferiu, para a Igreja Católica no Brasil, a experiência e as estratégias de rearticulação elaboradas na Europa durante a segunda metade do século XIX, perante o desafio de inserir-se no mundo saído da revolução intelectual e política do fim do século XVIII e com os regimes de liberdade civil e religiosa presentes nas teses liberais.

Segundo AUBERT(1978, p.7-26), o movimento de centralização da Igreja católica não partiu apenas de Roma. Um número cada vez maior de bispos, e sobretudo de padres e leigos envolvidos na ação católica, descobriu as vantagens que havia, para as igrejas particulares, de se apoiar em Roma., igrejas estas que, abandonadas a si mesmas, se encontravam muito mais expostas às pressões governamentais; muitos além disso, davam-se conta de que, num mundo em que problemas se colocavam cada vez mais num plano supranacional, a ligação com autonomias regionais era um aspecto ultrapassado.

A centralização em Roma das atividades religiosas e políticas da Igreja Católica, permitiu dar mais autonomia às paróquias. As atividades pastorais tendo como centro a paróquia, deste período em diante, apresentam-se como um conjunto de obras, como associações profissionais, associações recreativas, grupos devocionais, etc. Dentre estas obras a escola é a mais importante. Já que o universo social não é mais oficialmente cristão, criam-se ambientes nos quais a vida dos católicos possa desenvolver-se segundo a orientação da Igreja, livre de "erros" sócio-culturais condenados pelos papas. Dentro desta concepção, as paróquias serviriam para organizar toda a vida coletiva dos católicos, afastando-se de grupos socialistas, "anárquicos" e outras formas de 
organização que exprimiam doutrinas contrárias à Igreja.

Assim, a preocupação de reconstituir " ambientes cristãos", em função dos católicos, vivendo num mundo em vias de secularização, é responsável pelo desenvolvimento do ensino católico. Na medida em que a instrução se generalizava e era assumida pelos Estados, a partir de uma orientação secularizada, o clero católico, com apoio explícito da Santa Sé, passa a constituir to da uma rede de estabelecimentos de ensino, como parte de suas atividades pastorais. Tal rede de estabelecimentos de ensino, paralela ou antagônica ao ensino oficial, incluía já no final do século XIX, universidades na Bélgica (1834), na Irlanda (1851), na França (1875) e nos Estados Unidos (1887). Tal modelo pastoral é transplantado para todos os países com presença católica, como forma de garantir a hegemonia social, isto é, a direção intelectual e moral dos católicos.

\section{IV - Considerações pinnis}

O que acabamos de ver, é um relatório parcial da análise críticointerpretativa da bibliografia secundária consultada. Falta-nos, ainda, concluir o levantamento bibliográfico das fontes secundárias, em especial referentes ao Estado do Paraná, região de Curitiba, e dar início, a partir do quadro acima e sua complementação, ao levantamento das fontes primárias.

\section{Referências bibliográficas}

1. GRAMSCI, Antonio. Quaderni del carcere: Torino. Ed. Einaudi, 1975.

2. OLIVEIRA, Pedro Ribeiro. Religião e dominação de classe. Petrópolis,Vozes, 1985.

3. CARONE, Edgar. A República Velha I. São Paulo, DIFEL, 1978

4. . A República Velha II. Petrópolis, Vozes, 1983

5. FAORO, Raymundo. Os donos do poder I. São Paulo; Globo, 1997

6. HOLANDA, Sérgio B. História Geral da Civilização Brasileira. Vl. 2: São Paulo, DIFEL, 1968

7. AZZI, Riolando. O movimento brasileiro de reforma católica durantre 0 século XIX. In: Revista Eclesiástica Brasileira, vl. 34; 1974

8. AUBERT, Roger. Nova história da Igreja. A Igreja na sociedade liberal e no mundo moderno. Petrópolis, Vozes, 1962. 